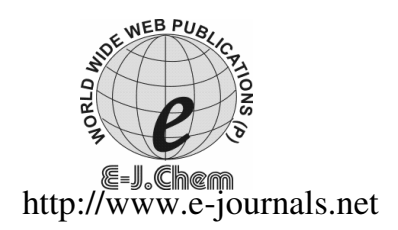

ISSN: 0973-4945; CODEN ECJHAO

E-Journal of Chemistry

2011, 8(4), 2000-2009

\title{
Study of Seasonal Variation in Groundwater Quality of Sagar City (India) by Principal Component Analysis
}

\author{
HEMANT PATHAK ${ }^{*}$ and S.N.LIMAYE \\ Department of Chemistry, "Indra Gandhi Govt. Engineering College, Sagar, India \\ Dr. Hari singh Gour Central University, Sagar (M.P.)- 470003, India \\ hemantp1981@yahoo.co.in
}

Received 9 January 2011; Accepted 1 March 2011

\begin{abstract}
Groundwater is one of the major resources of the drinking water in Sagar city (India.). In this study 15 sampling station were selected for the investigations on 14 chemical parameters. The work was carried out during different months of the premonsoon, monsoon and post-monsoon seasons in June 2009 to June 2010. The multivariate statistics such as principal component and cluster analysis were applied to the datasets to investigate seasonal variations in groundwater quality. Principal axis factoring has been used to observe the mode of association of parameters and their interrelationships, for evaluating water quality. Average value of BOD, COD, ammonia and iron was high during entire study period. Elevated values of BOD and ammonia in monsoon, slightly more value of BOD in post-monsoon, BOD, ammonia and iron in pre-monsoon period reflected contribution on temporal effect on groundwater. Results of principal component analysis evinced that all the parameters equally and significantly contribute to groundwater quality variations. Factor 1 and factor 2 analysis revealed the DO value deteriorate due to organic load (BOD/Ammonia) in different seasons. Hierarchical cluster analysis grouped 15 stations into four clusters in monsoon, five clusters in post-monsoon and five clusters in pre-monsoon with similar water quality features. Clustered group at monsoon, postmonsoon and pre-monsoon consisted one station exhibiting significant spatial variation in physicochemical composition. The anthropogenic nitrogenous species, as fallout from modernization activities. The study indicated that the groundwater sufficiently well oxygenated and nutrient-rich in study places.
\end{abstract}

Keywords: Multivariate statistics, Chemical parameters, Principal component analysis

\section{Introduction}

Good drinking water quality is essential for the well-being of all people which has affected the health and economic status of the populations. Groundwater is the major source of water 
for drinking, agricultural and industrial desires ${ }^{1}$. In this study, concentrations of chemical parameters such as $\mathrm{pH}, \mathrm{DO}, \mathrm{BOD}, \mathrm{COD}$, alkalinity, chloride, o-phosphate, nitrate, TDS, conductivity, $\mathrm{TH}$, fluoride, ammonia and iron in groundwater samples were determined by using standard analytical methods ${ }^{2}$. Multivariate analysis is a statistical technique for simultaneous analysis of two or more variables observed from one or more sample objects. The main objective of this analysis was to estimate the extent or amount of relationship among the variables along with the study of mean, deviation, variance and some other characteristics ${ }^{3}$. Principal component analysis, factor analysis, cluster analysis and similarity matrix analysis are the main components of the interdependent multivariate analysis and are also called data reduction techniques. Multivariate statistical techniques help in the interpretation of complex data matrices to better understand the water quality and ecological status of the studied systems and allows for identification of the possible factors that are responsible for the variations in water quality and offer valuable tool for developing appropriate strategies for effective management of the water resources ${ }^{4}$. The objective of the study was to analyze the 14 parameters of water along 15 locations of Sagar city for 3 seasons (pre-monsoon, monsoon and post-monsoon during June 2009 June 2010). The obtained water quality data was subjected to multivariate statistical techniques to evaluate homogeneity and heterogeneity between sampling stations and to differentiate water quality variables for temporal variations in the Sagar city ${ }^{5}$.

\section{Experimental}

All the chemicals used were of AR grade. Analysis was carried out for various water quality parameters (Table 1) were measured by using Standard methods. Sagar city was chosen as study area, 15 locations were selected based on domestic, agricultural and industrial activities. Water samples were collected from 15 stations for pre to post-monsoon seasons, three each during June 2009 to June 2010 by using standard methods (APHA). Results obtained were subjected to multivariate statistical analysis ${ }^{10-11}$ using SPSS.11, Winks SDA 6.0.5 and MVSP statistical software. The multivariate statistical analysis has been performed using standard methods.

Table 1. List of Chemical parameters and their test methods

\begin{tabular}{|c|c|c|c|}
\hline S.No. & Parameters & Unit & Test methods \\
\hline 1 & $\mathrm{pH}$ & - & $\mathrm{pH}$ meter \\
\hline 2 & Dissolved Oxygen (DO) & $\mathrm{mg} / \mathrm{L}$ & Winkler method \\
\hline 3 & $\begin{array}{l}\text { Biochemical Oxygen Demand } \\
\text { (BOD) }\end{array}$ & $\mathrm{mg} / \mathrm{L}$ & $\begin{array}{l}5 \text { days incubation at } 20^{\circ} \mathrm{C} \text { and } \\
\text { titration of initial and final DO. }\end{array}$ \\
\hline 4 & Chemical Oxygen Demand & $\mathrm{mg} / \mathrm{L}$ & Open reflux method \\
\hline 5 & Conductivity & $\mathrm{mho} / \mathrm{cm}$ & Conductivity meter \\
\hline 6 & Alkalinity & $\mathrm{mg} / \mathrm{L}$ & Titration \\
\hline 7 & Total dissolved Solids & $\mathrm{mg} / \mathrm{L}$ & Digital conductivity meter (LT-51) \\
\hline 8 & Chloride & $\mathrm{mg} / \mathrm{L}$ & Argentometric titration \\
\hline 9 & Orthophosphate $\left(\mathrm{PO}_{4}{ }^{3-}-\mathrm{P}\right)$ & $\mathrm{mg} / \mathrm{L}$ & $\begin{array}{l}\text { Ammonium molybdate ascorbic acid } \\
\text { reduction method }\end{array}$ \\
\hline 10 & Nitrate -Nitrogen $\left(\mathrm{NO}_{3}-\mathrm{N}\right)$ & $\mathrm{mg} / \mathrm{L}$ & Spectrophotometric method \\
\hline 11 & Ammonia-Nitrogen $\left(\mathrm{NH}_{3}-\mathrm{N}\right)$ & $\mathrm{mg} / \mathrm{L}$ & $\begin{array}{l}\text { Spectrophotometric (Phenate } \\
\text { method) }\end{array}$ \\
\hline 12 & Total Hardness as $\mathrm{CaCO}_{3}$ & $\mathrm{mg} / \mathrm{L}$ & EDTA titration \\
\hline 13 & Fluoride & $\mathrm{mg} / \mathrm{L}$ & Colorimetric method \\
\hline 14 & Iron & $\mathrm{mg} / \mathrm{L}$ & Colorimetric method \\
\hline
\end{tabular}




\section{Study area and collection of water samples}

Groundwater samples were collected from in and around Sagar city. Each water sample was taken every month during June 2009 to June 2010. The samples were collected in prewashed (with detergent, diluted $\mathrm{HNO}_{3}$ and doubly de-ionized distilled water, respectively) clean polythene bottles without any air bubbles and tightly sealed after collection and labeled in the field. The temperatures of the samples were measured in the field on the spot at the time of sample collection. The samples were immediately analysed in the chemistry lab to minimize physicochemical changes. The error due to time has been omitted for the present study ${ }^{6}$. Determinations of the major ions, physical and other chemical properties of the water samples were performed on the same day of sampling. Each sample was analysis using procedures outline in the standard methods for the examination of water and wastewater as suggested in $\mathrm{APHA}^{7}$. Chemical analysis results compared with standard guideline produced by $\mathrm{WHO}^{8} / \mathrm{IS}: 10500^{9}$.

\section{Results and Discussion}

Descriptive statistics (minimum, maximum, mean and standard deviation) of each data set of chemical parameters is given in Table 2, 5 and 8 .

\section{Seasonal analysis}

Mean values were taken into consideration as characteristic values to see the differences during 3 different seasons (Table 2, 5 and 8). The average values of BOD, ammonia and iron recorded highest in monsoon compare to post-monsoon, which could be due to acidification of water by elevated microbial degradation of organic debris and concentrated dissolved solids in monsoon period. As a momentous role of DO amount in water quality of groundwater, the average concentration of DO was highest in post-monsoon period (inversely proportional to temperature) and lowest in monsoon (Increase in phytoplankton and microbial activity) consequently increase in BOD and COD. DO value slightly more at pre-monsoon,

Table 2. Descriptive statistics (At monsoon)

\begin{tabular}{cccccccc}
\hline Field $^{*}$ & $\mathrm{~N}$ & Mean & Std & SEM & Min & Max & Sum \\
\hline- & - & - & - & - & - & - & - \\
pH & 15 & 7.7307 & 0.4841 & 0.1250 & 6.820 & 8.260 & 115.960 \\
DO & 15 & 5.9713 & 1.1893 & 0.3071 & 3.050 & 7.440 & 89.570 \\
BOD & 15 & 4.9787 & 1.1897 & 0.3072 & 2.640 & 6.850 & 74.680 \\
COD & 15 & 9.5700 & 1.0252 & 0.2647 & 8.480 & 11.760 & 143.550 \\
Conductivity & 15 & 0.7000 & 0.0944 & 0.0244 & 0.520 & 0.800 & 10.500 \\
Alkalinity & 15 & 192.000 & 32.768 & 8.461 & 126 & 246 & 2880 \\
TDS & 15 & 426.725 & 57.069 & 14.735 & 318.850 & 488.69 & 6400.87 \\
Chloride & 15 & 36.292 & 10.277 & 2.654 & 23.520 & 68.140 & 544.380 \\
Phosphate & 15 & 1.6453 & 0.5373 & 0.1387 & 0.830 & 2.590 & 24.680 \\
Nitrate & 15 & 1.6987 & 0.5928 & 0.1531 & 1.090 & 3.210 & 25.480 \\
Ammonia & 15 & 0.1987 & 0.0711 & 0.0184 & 0.110 & 0.350 & 2.980 \\
TH & 15 & 210.618 & 23.539 & 6.078 & 163.800 & 258.78 & 3159.27 \\
Fluoride & 15 & 0.8967 & 0.3718 & 0.0960 & 0.260 & 1.390 & 13.450 \\
Iron & 15 & 0.3913 & 0.1826 & 0.0471 & 0.180 & 0.970 & 5.870 \\
\hline \multicolumn{7}{c}{ The values (except conductivity; ${\text { mho } \mathrm{cm}^{-1} \text { ) are in } \mathrm{mg} / \mathrm{L}}$}
\end{tabular}


Table 3. Similarity matrix

\begin{tabular}{|c|c|c|c|c|c|c|c|c|c|c|c|c|c|c|}
\hline & $\mathrm{pH}$ & DO & BOD & $\mathrm{COD}$ & Cond & Alkali & TDS & Chloride & Phosp & Nitrate & Amm & $\mathrm{TH}$ & Fluoride & Iron \\
\hline $\mathrm{pH}$ & 0.234 & & & & & & & & & & & & & \\
\hline DO & 0.213 & 1.414 & & & & & & & & & & & & \\
\hline BOD & -0.034 & 0.317 & 1.415 & & & & & & & & & & & \\
\hline COD & 0.038 & -0.011 & 0.418 & 1.051 & & & & & & & & & & \\
\hline Cond & 0.016 & 0.073 & 0.064 & 0.043 & 0.009 & & & & & & & & & \\
\hline Alkali & 4.326 & 16.92 & 21.26 & 1.041 & 2.008 & 1073. & & & & & & & & \\
\hline TDS & 9.867 & 44.62 & 39.17 & 26.26 & 5.343 & 1222 & 3256. & & & & & & & \\
\hline Chloride & 0.728 & 0.611 & 6.711 & 1.364 & 0.443 & 107.0 & 269.8 & 105.6 & & & & & & \\
\hline Phosp & -0.022 & -0.176 & 0.135 & -0.184 & -0.004 & 5.068 & -2.675 & 0.732 & 0.288 & & & & & \\
\hline Nitrate & -0.11 & 0.277 & 0.317 & 0.136 & 0.011 & -0.197 & 7.004 & 0.022 & -0.084 & 0.351 & & & & \\
\hline Amm & -0.009 & -0.016 & -0.033 & -0.034 & -0.004 & -1.367 & -2.176 & -0.011 & 0.007 & 0.002 & 0.005 & & & \\
\hline TH & -5.225 & -9.638 & -4.718 & 2.303 & -0.83 & -325.9 & -505.6 & -1.694 & 1.764 & 1.009 & 0.944 & 554.10 & & \\
\hline Fluoride & 0.052 & 0.238 & 0.14 & -0.171 & 0.015 & 6.001 & 8.841 & 1.78 & 0.013 & 0.019 & 0 & -2.366 & 0.138 & \\
\hline Iron & 0.028 & -0.015 & 0.066 & -0.026 & -0.002 & 1.247 & -0.972 & 0.625 & 0.03 & -0.002 & 0.003 & 0.11 & 0.025 & 0.033 \\
\hline
\end{tabular}

Table 4. Principal components analysis

\begin{tabular}{|c|c|c|c|c|c|}
\hline \multicolumn{6}{|c|}{ Tolerance of eigenanalysis set at $1 \mathrm{E}-007$} \\
\hline \multicolumn{6}{|c|}{ Eigenvalues } \\
\hline & & & \multicolumn{2}{|c|}{ Axis 1} & Axis 2 \\
\hline Eigenvalues & & & \multicolumn{2}{|c|}{3932.041} & 88.517 \\
\hline Percentage & & & \multicolumn{2}{|c|}{78.716} & 11.782 \\
\hline Cum. Percentage & & & \multicolumn{2}{|c|}{78.716} & 90.498 \\
\hline \multicolumn{3}{|c|}{ PCA variable loadings } & \multicolumn{3}{|c|}{ PCA case scores } \\
\hline & Axis1 & Axis 2 & & Axis 1 & Axis 2 \\
\hline A-pH & 0.003 & -0.004 & A-1 & -34.76 & 5.878 \\
\hline B-DO & 0.012 & 0.003 & B-2 & 9.34 & 6.896 \\
\hline C-BOD & 0.011 & -0.004 & $\mathrm{C}-3$ & -19.075 & 8.651 \\
\hline D-COD & 0.006 & 0.02 & D-4 & -26.26 & -5.03 \\
\hline E-Conductivity & 0.002 & -0.001 & E-5 & -13.827 & -6.117 \\
\hline F-Alkalinity & 0.405 & -0.716 & F-6 & 17.338 & 3.997 \\
\hline G-TDS & 0.894 & 0.424 & G-7 & 5.564 & 8.126 \\
\hline H-Chloride & 0.074 & 0.076 & H-8 & 16.045 & 3.66 \\
\hline I-Phosphate & 0 & -0.007 & I-9 & 20.587 & -2.968 \\
\hline J-Nitrate & 0.002 & 0.005 & $\mathrm{~J}-10$ & -3.248 & 0.439 \\
\hline K-Ammonia & -0.001 & 0 & $\mathrm{~K}-11$ & 2.057 & -5.233 \\
\hline L-TH & -0.173 & 0.549 & $\mathrm{~L}-12$ & 9.171 & -2.249 \\
\hline M-Fluoride & 0.003 & -0.003 & M-13 & 15.403 & -3.746 \\
\hline N- Iron & 0 & -0.001 & $\mathrm{~N}-14$ & -3.725 & -14.586 \\
\hline & & & $\mathrm{O}-15$ & 5.39 & 2.283 \\
\hline
\end{tabular}


Table 5. Descriptive statistics (At post- monsoon)

\begin{tabular}{ccccllll}
\hline Field & $\mathrm{N}$ & \multicolumn{1}{c}{ Mean } & \multicolumn{1}{c}{ Std } & \multicolumn{1}{c}{ SEM } & \multicolumn{1}{c}{ Min } & \multicolumn{1}{c}{ Max } & \multicolumn{1}{c}{ Sum } \\
\hline- & - & - & - & - & - & - & - \\
pH & 15 & 8.1347 & 0.2477 & 0.0640 & 7.510 & 122.020 & 122.020 \\
DO & 15 & 7.4427 & 0.8130 & 0.2099 & 5.740 & 8.320 & 111.640 \\
BOD & 15 & 3.1707 & 1.6289 & 0.4206 & 2 & 8.650 & 47.560 \\
COD & 15 & 8.8580 & 1.9392 & 7.350 & 7.350 & 15.250 & 132.870 \\
Conductivity & 15 & 0.6327 & 0.0788 & 0.0203 & 0.500 & 0.800 & 9.490 \\
Alkalinity & 15 & 178.400 & 34.265 & 8.847 & 112 & 248 & 2676 \\
TDS & 15 & 375.012 & 57.285 & 14.791 & 302.850 & 488.63 & 5625.18 \\
Chloride & 15 & 30.235 & 8.802 & 2.273 & 19.960 & 52.400 & 453.520 \\
Phosphate & 15 & 1.1587 & 0.3421 & 0.0883 & 0.780 & 1.830 & 17.380 \\
Nitrate & 15 & 1.5787 & 0.4843 & 0.1250 & 0.1250 & 0.380 & 2.480 \\
Ammonia & 15 & 0.1813 & 0.0593 & 0.0153 & 0.110 & 0.310 & 2.720 \\
TH & 15 & 195.011 & 24.564 & 6.342 & 158.290 & 239.13 & 2925.16 \\
Fluoride & 15 & 0.8680 & 0.3643 & 0.0941 & 0.230 & 1.370 & 13.020 \\
Iron & 15 & 0.2893 & 0.1173 & 0.0303 & 0.140 & 0.560 & 4.340 \\
\hline
\end{tabular}

Table 6. Similarity matrix

\begin{tabular}{ccccccccccccccc}
\hline & $\mathrm{pH}$ & $\mathrm{DO}$ & BOD & COD & Cond & Alkali & TDS & $\mathrm{Cl}$ & Phos & Nitrat & Amm & TH & F & Iron \\
\hline pH & 0.061 & & & & & & & & & & & & & \\
DO & -0.02 & 0.661 & & & & & & & & & & & \\
BOD & 0.119 & 0.242 & 2.653 & & & & & & & & & & & \\
COD & -0.01 & 0.303 & 2.693 & 3.761 & & & & & & & & & & \\
Cond & 0.011 & 0.001 & 0.006 & -0.03 & 0.006 & & & & & & & & & \\
Alkali & 3.829 & 3.572 & 31.88 & 18.04 & 0.134 & 1174 & & & & & & & & \\
TDS & 2.877 & 16.25 & -17.4 & -61.2 & 0.808 & 795.4 & 3281 & & & & & & & \\
Cl & -0.60 & 1.656 & -1.00 & -1.66 & -0.01 & 24.05 & 142.5 & 77.47 & & & & & & \\
Phos & 0.001 & -0.061 & -0.126 & -0.274 & -0.007 & 3.088 & 8.985 & -0.67 & 0.117 & & & & & \\
Nitrat & 0.009 & 0.223 & 0.133 & 0.047 & 0 & 5.033 & 9.645 & -0.63 & 0.028 & 0.235 & & & & \\
Amm & -0.001 & -0.014 & -0.017 & -0.023 & 0 & -0.172 & 0.311 & 0.189 & 0.001 & -0.01 & 0.004 & & & \\
TH & -3.32 & -7.07 & -18.9 & -12.2 & 0.058 & -436 & -300 & 92.87 & -2.04 & -4.61 & 0.304 & 603.3 & & \\
F & 0.07 & 0.074 & 0.113 & -0.158 & 0.018 & 6.489 & 11.65 & 0.391 & -0.008 & 0.052 & 0 & -4.41 & 0.133 & \\
Iron & 0.002 & 0.003 & -0.059 & -0.011 & 0 & -0.69 & -1.61 & 0.005 & -0.008 & -0.021 & -0.002 & 0.271 & -0.006 & 0.014 \\
\hline
\end{tabular}

The values (except conductivity; $m$ ho $\mathrm{cm}^{-1}$ ) are in $\mathrm{mg} / \mathrm{L}$

It might be due to copious growth of phytoplankton with less water flow, disturbance and uprooting leading to increased generation of $\mathrm{O}_{2}$ by photosynthetic activities. TH was recorded comparatively highest in pre-monsoon and lowest in post-monsoon (beyond desirable limit prescribed ${ }^{9}$ by IS: 10500). Alkalinity values are mostly exhibited higher values in pre-monsoon and lowest in post-monsoon. Application of chemical fertilizers, run off from agricultural field, leaching of industrial/domestic waste and sewage inflow and other anthropogenic sources are the possible point and non point sources of groundwater.

Average phosphate ranged from 1.158 to $1.645 \mathrm{mg} / \mathrm{L}$, fluoride (F-) varied from 0.86 to $1.029 \mathrm{mg} / \mathrm{L}$. Permissible limit for F concentration is $1-1.5 \mathrm{mg} / \mathrm{L}$, according to WHO. The data revealed that all the sources had lower $F$-values. Nitrate in the investigated samples were found to be in a range of 1.57 to $1.67 \mathrm{mg} / \mathrm{L}$ and $o$-phosphate 0.86 to $1.028 \mathrm{mg} / \mathrm{L}$ respectively. The range of chloride in the samples was 30.23 to $36.29 \mathrm{mg} / \mathrm{L}$ at throughout the sampling periods. The range of iron in the samples was .289 to $.402 \mathrm{mg} / \mathrm{L}$. 
Concentrations were all below the WHO permissible limits. The concentrations of the major ions were below the permissible limits given ${ }^{9}$ by the WHO/IS: 10500. The lowest and the highest levels of these iron detected ranged between 0.289 to $0.402 \mathrm{mg} / \mathrm{L}$. Average Hardness levels were found to be in the water samples were below the WHO permitted limit, which is $213.11 \mathrm{mg} / \mathrm{L}$.

\section{Factor analysis}

Principal component analysis/factor analysis was performed on 14 variables for the 15 different sampling stations in 3 seasons, in order to identify imperative seasonal water quality parameters. The principal component analysis results along with factor loading values and percentage of variance for all stations are presented in Table 4, 7, 10. An eigen value gives a measure of the significance of the factor: the factor with highest eigen values are the most significant. Eigen values of 1.0 or greater are considered significant. Factor loading is classified as strong, moderate and weak corresponding to absolute loading values of $>0.75,0.75-0.50$ and $0.50-0.30$ respectively. Two factors or PCs explained $90.5,91.6$ and $89 \%$ of the total variance for monsoon to pre-monsoon respectively, which was adequate to give a good initiative of the data structure. Factor 1 of the monsoon accounted for $78.7 \%$ of the total variance, which was positively and strongly $(>0.75)$ loaded with eigen values of almost all the parameters except weak loading $(.012<0.5)$ of DO. Whereas in the case of post-monsoon factor 1 exhibited moderate $(0.75-0.5)$ and positive factor loading of all the parameters except BOD, Ammonia and Iron with $70.25 \%$ of the total variance was observed. The first factor in all the seasons only TDS was exhibiting more than 0.8 , indicating strong and positive association. In this study each water quality parameter with a strong eigen value $(>75 \%)$ was considered to be a significant parameter contributing to temporal variations of the water quality in Sagar city. Both organic and inorganic parameters equally contributing and strong factor loadings in water quality variations for 3 seasons.

Table 7. Principal components analysis

\begin{tabular}{lll}
\hline Eigenvalues & & \\
& Axis 1 & Axis 2 \\
\hline Eigenvalues & 3614.08 & 1098.275 \\
Percentage & 70.256 & 21.35 \\
Cum. Percentage & 70.256 & 91.606 \\
\hline
\end{tabular}

\begin{tabular}{lcc}
\hline \multicolumn{3}{c}{ PCA variable loadings } \\
\hline & Axis1 & Axis 2 \\
A-pH & 0.002 & 0.004 \\
B-DO & 0.005 & 0.001 \\
C-BOD & -0.001 & 0.037 \\
D-COD & -0.014 & 0.038 \\
E-Conductivity & 0 & 0 \\
F-Alkalinity & 0.329 & 0.787 \\
G-TDS & 0.933 & -0.349 \\
H-Chloride & 0.036 & -0.076 \\
I-Phosphate & 0.003 & 0 \\
J-Nitrate & 0.003 & 0.003 \\
K-Ammonia & 0 & 0 \\
L-TH & -0.14 & -0.499 \\
M-Fluoride & 0.004 & 0.004 \\
N- Iron & 0 & 0 \\
\hline
\end{tabular}

\begin{tabular}{ccc}
\hline \multicolumn{3}{c}{ PCA case scores } \\
\hline & Axis 1 & Axis 2 \\
A-1 & -21.784 & -13.414 \\
B-2 & 2.647 & -4.371 \\
C-3 & -22.142 & -5.539 \\
D-4 & -20.738 & -2.431 \\
E-5 & -10.053 & 4.843 \\
F-6 & 13.275 & -0.327 \\
G-7 & 3.293 & -5.477 \\
H-8 & 1.774 & -6.896 \\
I-9 & 31.891 & -2.741 \\
J-10 & 6.796 & -3.397 \\
K-11 & 7.648 & 3.2 \\
L-12 & 13.245 & 1.87 \\
M-13 & 18.041 & 1.89 \\
N-14 & -9.405 & 26.079 \\
O-15 & -14.487 & 6.711 \\
\hline
\end{tabular}


Table 8. Descriptive statistics (At pre-monsoon)

\begin{tabular}{cccccccc}
\hline Field $^{*}$ & $\mathrm{~N}$ & Mean & Std & SEM & Min & Max & Sum \\
\hline- & - & - & - & - & - & - & - \\
pH & 15 & 8.2460 & 0.2447 & 0.0632 & 7.740 & 8.520 & 123.690 \\
DO & 15 & 5.9960 & 5.9960 & 0.2987 & 4.140 & 7.350 & 89.940 \\
BOD & 15 & 4.2493 & 2.3918 & 0.6176 & 2.180 & 12.250 & 63.740 \\
COD & 15 & 9.5053 & 2.3659 & 0.6109 & 7.650 & 17.260 & 142.580 \\
Conductivi & 15 & 0.6520 & 0.0811 & 0.0209 & 0.520 & 0.810 & 9.780 \\
Alkalinity & 15 & 212.667 & 31.181 & 8.051 & 170 & 274 & 3190 \\
TDS & 15 & 396.047 & 56.817 & 14.670 & 313.490 & 491.53 & 5940.70 \\
Chloride & 15 & 32.377 & 9.142 & 2.361 & 20.430 & 60.350 & 485.660 \\
Phosphate & 15 & 1.5980 & 0.6985 & 0.1804 & 0.550 & 2.830 & 23.970 \\
Nitrate & 15 & 1.5947 & 0.2623 & 0.0677 & 1.260 & 2.240 & 23.920 \\
Ammonia & 15 & 0.2033 & 0.0558 & 0.0144 & 0.110 & 0.290 & 3.050 \\
TH & 15 & 233.707 & 27.323 & 7.055 & 188.360 & 282.34 & 3505.60 \\
Fluoride & 15 & 1.0293 & 0.4573 & 0.1181 & 0.240 & 1.820 & 15.440 \\
Iron & 15 & 0.4027 & 0.0888 & 0.0229 & 0.250 & 0.550 & 6.040 \\
\hline
\end{tabular}

Table 9. Similarity matrix

\begin{tabular}{|c|c|c|c|c|c|c|c|c|c|c|c|c|c|}
\hline & $\mathrm{pH}$ & DO & BOD & COD & Cond & Alkali & TDS & Chloride & Phosp & Nitrat & Amm & TH Fluoride & Iron \\
\hline $\mathrm{pH}$ & 0.06 & & & & & & & & & & & & \\
\hline $\mathrm{DO}$ & 0 & 1.33 & & & & & & & & & & & \\
\hline BOD & 0.08 & 0.04 & 5.72 & & & & & & & & & & \\
\hline COD & -0.035 & -0.103 & 5.15 & 5.59 & & & & & & & & & \\
\hline Cond & 0.01 & 0.04 & 0.04 & -0.018 & 0.006 & & & & & & & & \\
\hline Alkali & -0.42 & 14.3 & -7.56 & -16.9 & 0.127 & 972.24 & & & & & & & \\
\hline TDS & 2.94 & 36.0 & -43 & -56.4 & 1.007 & 1144.9 & 3228. & & & & & & \\
\hline Chloride & 0.65 & 4.98 & -4.6 & -5.18 & 0.293 & 87.943 & 258.1 & 83.581 & & & & & \\
\hline Phosp & 0.084 & 0.29 & 0.638 & 0.39 & 0.023 & 11.585 & 9.764 & 3.044 & 0.488 & & & & \\
\hline Nitrat & -0.008 & -0.03 & -0.13 & -0.014 & -0.01 & 0.3 & 0.88 & -0.274 & -0.055 & 0.069 & & & \\
\hline Amm & -0.005 & 0.018 & -0.012 & 0.006 & -0.001 & 0.364 & 0.927 & 0.07 & -0.001 & 0.001 & 0.003 & & \\
\hline $\mathrm{TH}$ & -1.90 & 2.57 & -19.4 & -19.1 & -0.233 & -43.9 & -240.1 & -52.89 & -6.279 & 0.362 & 0.08 & 746 & \\
\hline Fluoride & 0.088 & 0.025 & -0.05 & -0.35 & 0.02 & 1.673 & 11.64 & 1.612 & 0.104 & -0.016 & -0.006 & -1.20 .209 & \\
\hline Iron & 0.007 & 0.015 & 0.005 & -0.009 & 0.001 & -0.053 & 1.308 & 0.276 & 0.001 & -0.001 & 0 & $0.16 \quad 0.009$ & 0.008 \\
\hline
\end{tabular}

Table 10. Principal components analysis

\begin{tabular}{lrc}
\hline \multicolumn{4}{c}{ Tolerance of eigen analysis set at 1E-007 } \\
\hline \multicolumn{3}{c}{ Eigen values } \\
Eigenvalues & Axis 1 & Axis 2 \\
Percentage & 3749.1 & 741.51 \\
Cum. Percentage & 74.327 & 14.701 \\
\hline
\end{tabular}




\begin{tabular}{ccc}
\hline \multicolumn{3}{c}{ PCA variable loadings } \\
\hline & Axis 1 & Axis 2 \\
A-pH & 0.001 & -0.002 \\
B-DO & 0.01 & 0.007 \\
C-BOD & -0.011 & -0.028 \\
D-COD & -0.015 & -0.03 \\
E-Conductivity & 0 & 0 \\
F-Alkalinity & 0.382 & 0.222 \\
G-TDS & 0.917 & -0.004 \\
H-Chloride & 0.075 & -0.05 \\
I-Phosphate & 0.004 & -0.005 \\
J-Nitrate & 0 & 0 \\
K-Ammonia & 0 & 0 \\
L-TH & -0.08 & 0.973 \\
M-Fluoride & 0.003 & 0 \\
N - Iron & 0 & 0 \\
\hline
\end{tabular}

Cluster analysis

\begin{tabular}{ccc}
\hline \multicolumn{3}{c}{ PCA case scores } \\
\hline & Axis 1 & Axis 2 \\
A-1 & -21.53 & 5.485 \\
B-2 & 7.253 & 4.074 \\
C-3 & -24.48 & 4.389 \\
D-4 & -21.47 & -2.507 \\
E-5 & -15.66 & -3.071 \\
F-6 & 15.445 & -2.949 \\
G-7 & 2.037 & -6.514 \\
H-8 & 2.963 & -2.337 \\
I-9 & 27.26 & 11.691 \\
J-10 & 0.028 & 11.802 \\
K-11 & 1.57 & 7.725 \\
L-12 & 14.481 & -8.019 \\
M-13 & 18.172 & -0.913 \\
N-14 & -16.67 & -5.915 \\
O-15 & 10.604 & -12.94 \\
\hline
\end{tabular}

The hierarchical tree diagram provides the analyst with an effective visual condensation of the clustering results. The hierarchical tree diagram is one of the most commonly used methods of determining the number of clusters. It is also useful in spotting outliers, as these will appear as one-member clusters that are joined later in the clustering process. The objective of cluster analysis is to separate the observations into different groups (clusters) so that the members of any one group differ from one another as little as possible, whereas observations across clusters tend to be dissimilar. The grouping can be used to summarize the data or as a basis for further analysis. The affiliation among the stations were obtained through cluster analysis using ward's method (linkage between groups), This method tends to join clusters with a small number of observations and is biased towards producing clusters with roughly the same number of observations, with euclidian distance as a similarity measure and were amalgamated into dendrogram plots (Figures 1 to 2). All chemical characteristics were used as variables to show the spatial heterogeneity among the stations as a result of sequence in their relationship and the degree of contamination. There were 4 groups obtained from the monsoon season while pre and post-monsoon season yielded five groups and the likely groupings are summarized below. The fourth group of monsoon, third group of post-monsoon and second group of pre-monsoon are consisted of one station respectively. In the monsoon season group 2 and group 3 were exhibiting similar variation in comparison with group 1, providing evidence that former two groups could be categorized as less polluted and latter as highly polluted, due to agricultural and urban run-off into the land. In the case of post-monsoon, increased number of linkages revealed spatial variation among the stations is noticeable and it could be due to inflow of contaminants from point and non-point sources through rain water. The number of stations clustered to form a group is in the sequence of $\mathrm{V}>\mathrm{I}>\mathrm{VII}>\mathrm{I}>\mathrm{I}$. The group clustered with a large number of stations construed the spatial similarity in their physicochemical composition amongst them, as influenced by urban run-off. Fourth clustered group of monsoon and third of post-monsoon, second of pre-monsoon consisted of unique station, exhibiting significant spatial variation in physicochemical composition. It related the degree of revelation to human interference and extent of pollutants. The number of clustered groups obtained through dendrogram for pre-monsoon and postmonsoon signifying temporal impact on the groundwater quality too. 


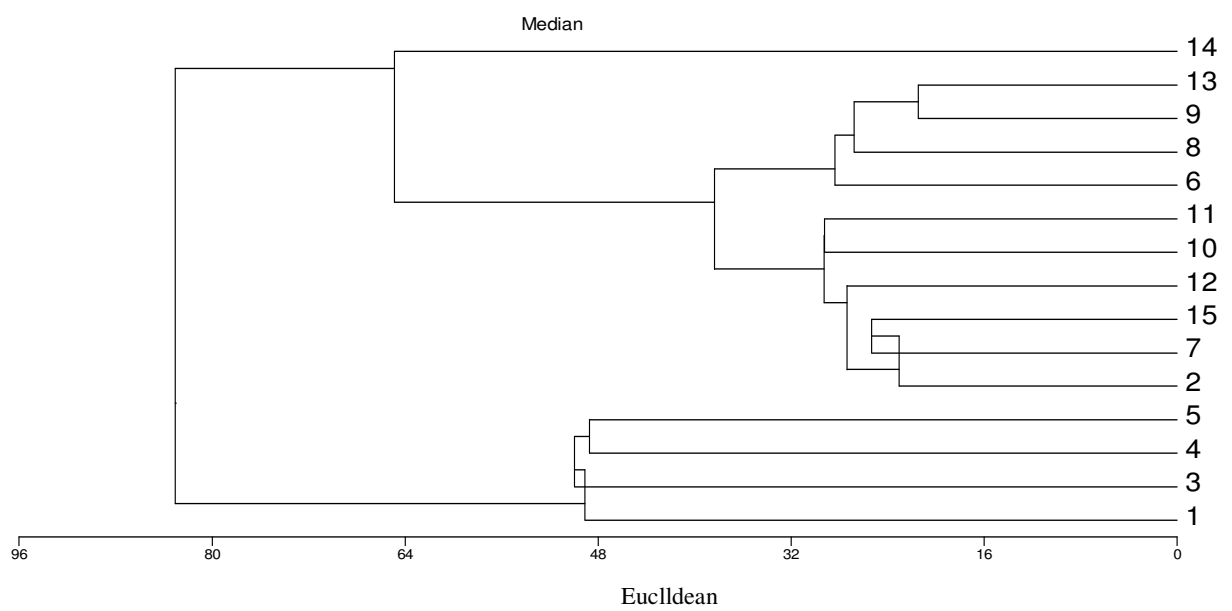

Figure 1. Monsoon

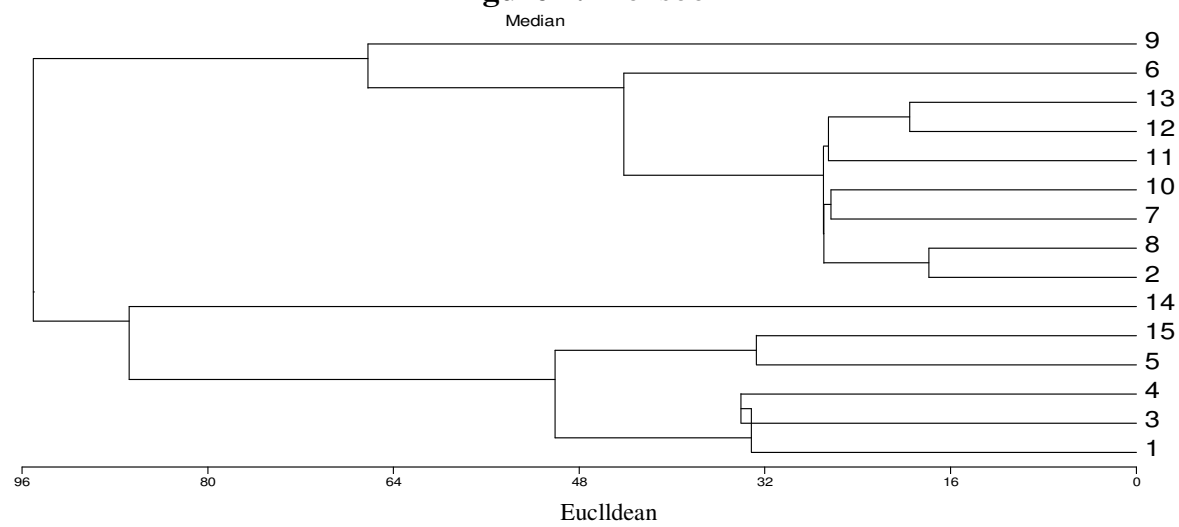

Figure 2. Post-monsoon

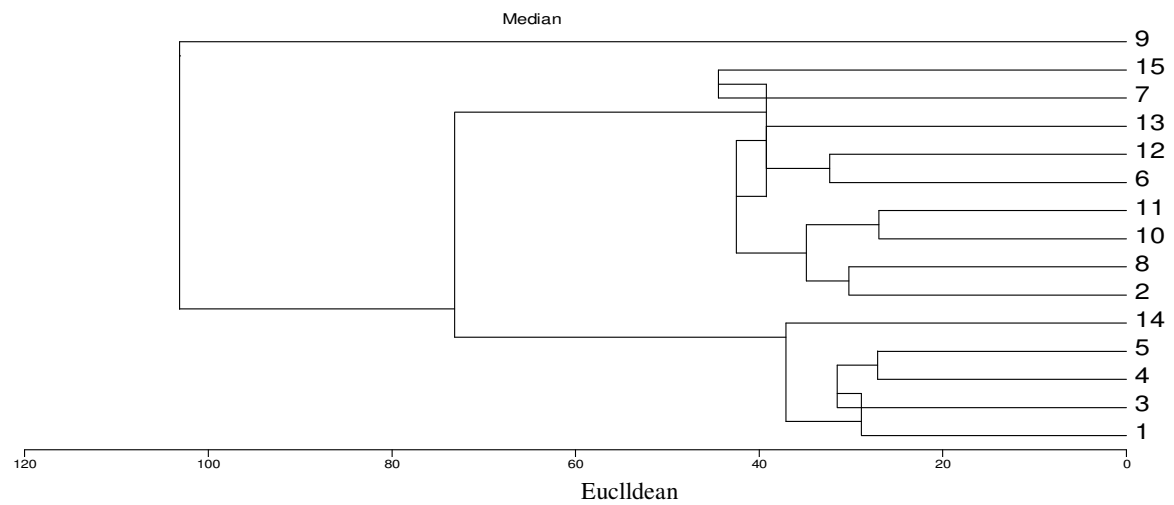

Figure 3. Pre-monsoon

\section{Conclusion}

Comparing the mean values of groundwater quality parameters of Sagar city it can be concluded that variables - TDS, TH are slightly higher and Alkalinity, $\mathrm{Cl}$ are lower in the 
post-monsoon period than in the pre-monsoon. On the other hand parameters - BOD, COD, ammonia and nitrate are clearly higher in all the season showed a clear cut temporal effect. Relation of TDS with other variables in factor 1 and strong positive association in factor 2 analysis signifies the role of TDS in determining water quality of the groundwater. By cluster analysis, it is proved that in entire study period alone formed a group with highest Euclidian distance compared to other cluster groups reflecting inflow of organic pollutants and extent of pollution. Second cluster group in monsoon, third cluster group in postmonsoon and fourth cluster group in pre-monsoon period as enunciated by Euclidian distance indicated the noticeable spatial variation among different stations. BOD is out of the highest desirable limit or maximum permissible limit set by WHO except TH, alkalinity and conductivity which recorded high values. Hence, these sample water can be absolutely fit for drinking after disinfectants treatment. The multivariate statistical analysis of the experimentally estimated water quality parameters on water samples yielded the range of the variation, mean, standard deviation and co-efficient of variation. Since the similarity matrix gives (c.f. Table 3, $6 \&$ \&) the interrelationship between the parameters, correlation coefficients were calculated. After regular monthly monitoring on Results of multivariate analysis show that, all applied water quality parameters are within the permissible limit ${ }^{8}{ }^{9}$ set by WHO/IS: 10500 .

The average of alkalinity has exceeded the desirable Limits, which are due to improper drainage system. In conclusion, from the results of the present study it may be said that groundwater analysis should be carried out from time to time to monitor the rate and kind of contamination. It is need of human to expand awareness among the people to maintain the groundwater at their highest quality and purity levels.

\section{References}

1. Lazhar B, Abdurrahman B, Lotfi M and Toufik B, African J Environ Sci Technol., 2010, 4(8), 526-534.

2. Ilangeswaran D, Kumar R and Kannan D, E-J Chem., 2009, 6(3), 898-904.

3. Mardia K V, Kent J T and Bibby J M, Multivariate Analysis (Academic Press), 1979, 180.

4. Kouping Chen, Jiu J Jiao and Jianmin Huang, Environ Poll., 2007, 147, 771-780.

5. Praus P, Water SA., 2005, 31(4), 417-422.

6. Ata S, Farid M, Zargham M and Ezzatollah R, World Applied Sciences Journal, 2009, 7(4), 522-530.

7. APHA, Standard methods for the examination of water and wastewater, $21^{\text {st }}$ Edition, American Public Health Association, Washington DC, USA, 2005.

8. W.H.O, Guidelines for drinking water quality, Vol.1, Recommendations WHO, Geneva, 1984.

9. Indian standard drinking water, Specification (First Revision) IS-10500:1991, BIS, New Delhi, India

10. $\quad$ SPSS Advanced Models ${ }^{\mathrm{TM}} 11.0$ at http://www.spss.com

11. WINKS SDA software, Version 6, at www.texasoft.com 


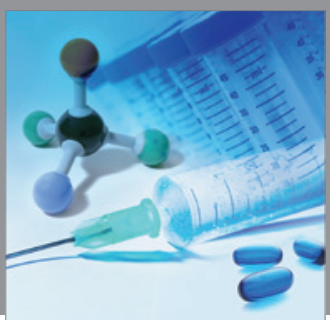

International Journal of

Medicinal Chemistry

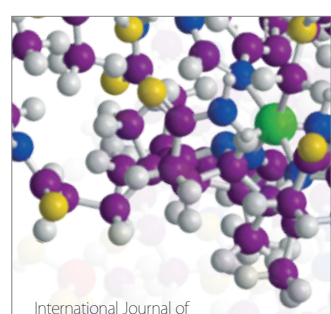

Carbohydrate Chemistry

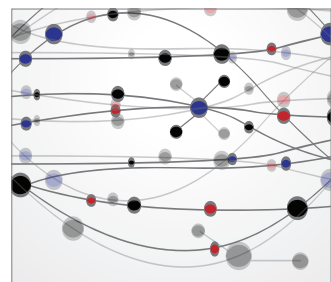

The Scientific World Journal
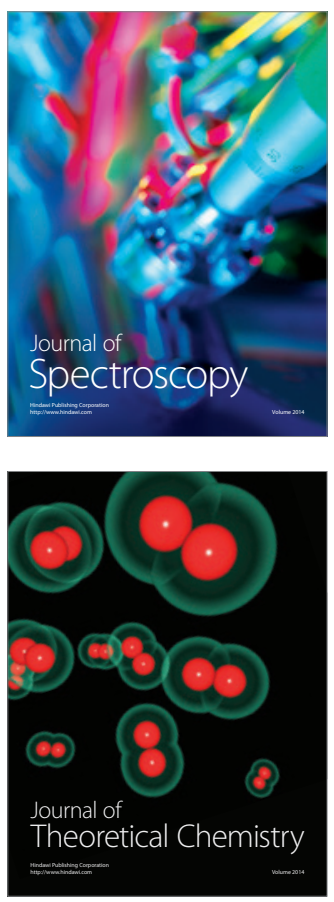
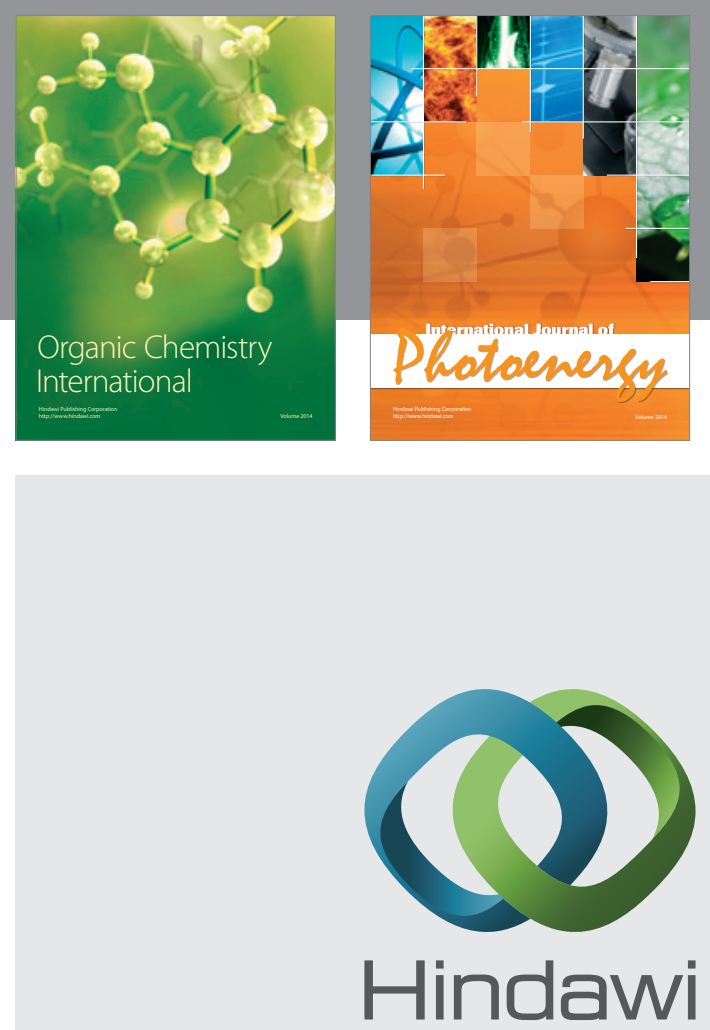

Submit your manuscripts at

http://www.hindawi.com
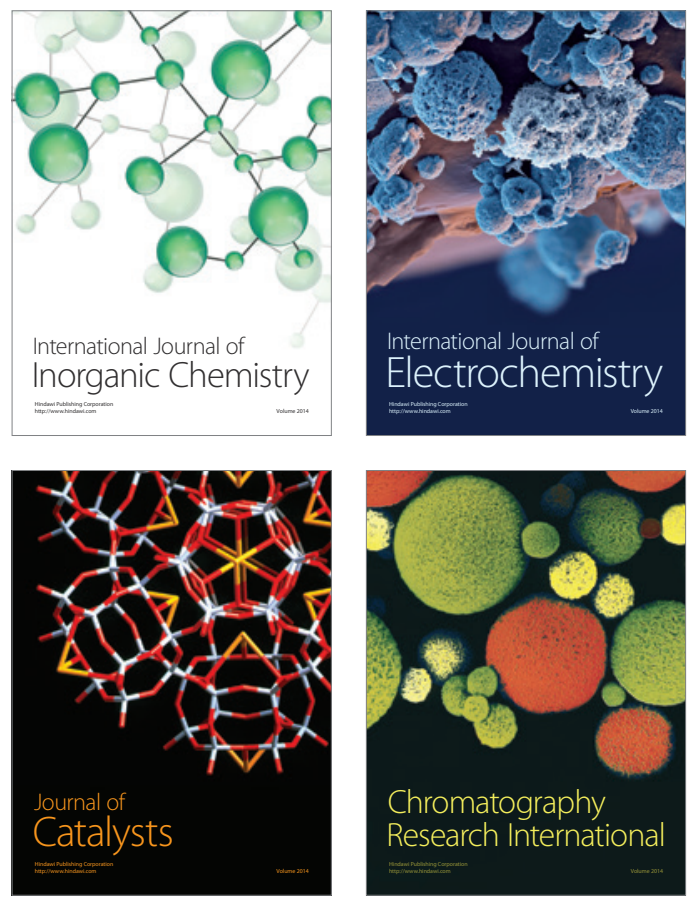
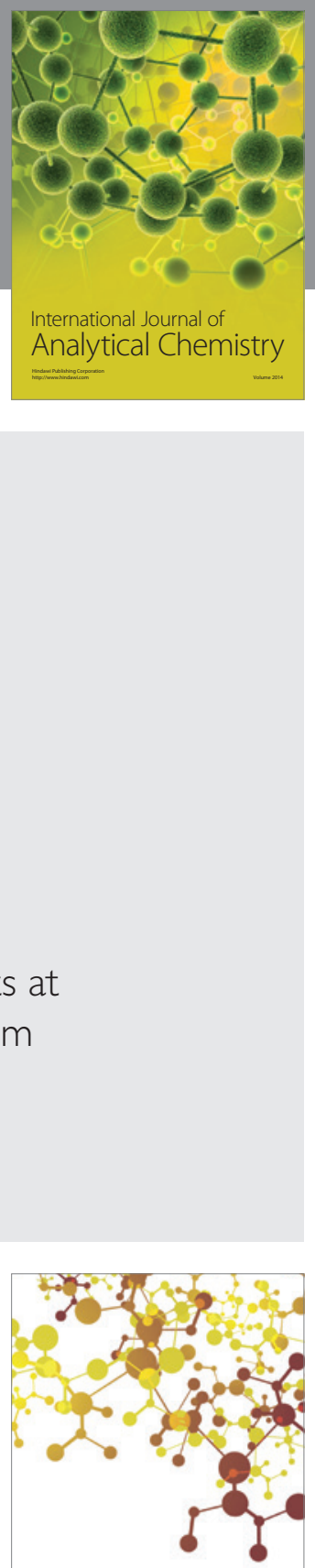

Journal of

Applied Chemistry
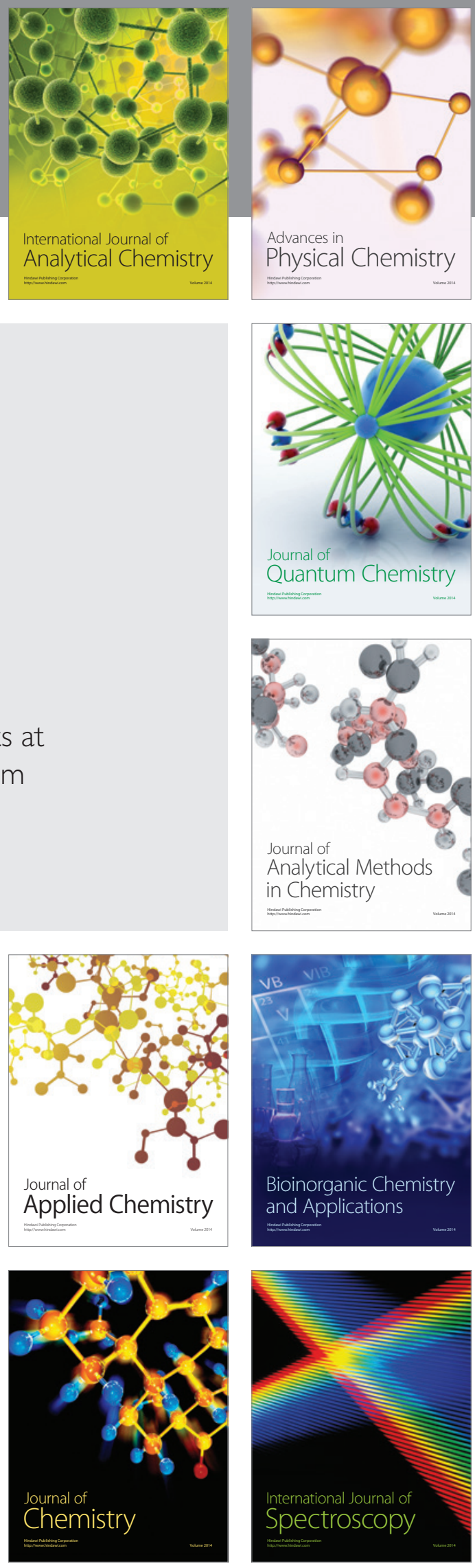